\title{
Suicide Attempts and Contributing Factors among South and North Korean-Family Youth Using the Korean Youth Risk Behavior Web-based Survey
}

\author{
Soo Jung Rim ${ }^{1,2}$, Min Geu Lee', and Subin Park \\ 'Department of Research Planning, Mental Health Research Institute, National Center for Mental Health, Seoul, Korea \\ ${ }^{2}$ Department of Psychology, Graduate School, Seoul National University, Seoul, Korea
}

\begin{abstract}
Objectives: There is an increasing number of North Korean adolescents in South Korea. These adolescents need clinical attention as they experience a high risk of suicidal behavior because of the childhood adversity and acculturative challenges that they face before and after arriving in South Korea. This study assessed the risk of suicide attempts among North Korean adolescents compared to South Korean adolescents, and investigated the contributing factors for each group.

Methods: We used data from the Korean Youth Risk Behavior Web-Based Survey (KYRBS) spanning 2011 to 2018, in which 404 adolescents had a father and/or mother who was a North Korean native. Data on 1,212 propensity-matched South Korean adolescents were extracted from the 2011 to 2018 KYRBS. Prevalence was calculated and compared by group. Separate odds ratios were calculated by group. Results: The North Korean group had a significantly higher suicide attempt rate [unadjusted odds ratio (OR)=8.27; adjusted $O R=8.45$ ]. Multivariate analysis indicated that having a low or high socioeconomic status and depressive symptoms were significantly associated with suicide attempts in North Korean adolescents, while being female, having a high socioeconomic status, alcohol use, and depressive symptoms were significantly related to suicide attempts in South Korean adolescents.

Conclusion: The results found similarities and differences in the factors associated with the likelihood of suicide attempts in the two groups. From these results, different approaches are needed when planning interventions for each group.
\end{abstract}

Key Words: North Korean-family; Adolescent; Suicide attempt; Contributing factors; KYRBS.

Received: October 17, 2019 / Revision: November 14, 2019 / Accepted: November 21, 2019

Address for correspondence: Subin Park, Department of Research Planning, Mental Health Research Institute, National Center for Mental Health, 127 Yongmasan-ro, Gwangjin-gu, Seoul 04933, Korea

Tel: +82-2-2-2204-0108, Fax: +82-2-2204-0362, E-mail: subin-21@hanmail.net

\section{INTRODUCTION}

Approximately 3,000 North Korean refugees settle in South Korea annually and, as of 2016, the total number of North Korean refugees or former refugees residing in South Korea exceeded 30,000 [1]. In the past, the vast majority of North Korean refugees were men seeking political asylum; however, the numbers of North Korean women and children seeking refuge have been increasing [2]. Recent statistics indicate that approximately $40 \%$ of all North Korean refugees in Korea are 10-29 years old [1].

North Korean adolescent refugees have often been exposed to and traumatized by terrible events in their life in North Korea, during their escape, and/or while settling in South Korea. In North Korea, many of them experienced malnutrition and physical or sexual violence [3]. During the escape, they en-

This is an Open Access article distributed under the terms of the Creative Commons Attribution Non-Commercial License (https://creativecommons.org/licenses/by-nc/4.0) which permits unrestricted non-commercial use, distribution, and reproduction in any medium, provided the original work is properly cited. dured the fear of being caught and imprisoned [4]. Since they entered South Korea, these adolescents have faced difficulties in adjusting to and dealing with culture shock, prejudice and discrimination, and poverty, and, consequently, their school dropout rates are high [4]. A considerable number of previous studies $[5,6]$ found that these adolescents have mental health problems, including depression, post-traumatic stress disorder, anxiety, and other emotional and behavioral problems. Moreover, North Korean adolescent refugees have higher rates of suicidal ideation [7] compared to South Korean adolescents. Therefore, the mental health of North Korean adolescent refugees needs to be given greater clinical attention.

One previous study [8] reported that $34 \%$ of people with suicidal ideations devise suicide plans and $72 \%$ of those who make such plans attempt suicide. Therefore, it is important to develop interventions to prevent suicidal behaviors. As the number of North Korean adolescent refugees in South Korea is increasing annually, it is important to investigate this group and the factors related to their suicide attempts. One recent 
study examined suicidal ideation and related factors among North Korean adolescent refugees [9], and another one [10] investigated the prevalence of suicide attempts among this group. Contributing factors associated with suicide attempts have been separately investigated for North Korean refugee adolescents and South Korean adolescents, since both groups have varied childhood experiences. However, to the best of our knowledge, no studies have jointly investigated suicide attempts and the contributing factors among North Korean adolescents living in South Korea, and compared them to those of their South Korean counterparts. Therefore, this study examined suicide attempts and the related factors among South and North Korean adolescents in families using data from the 2011-2018 Korean Youth Risk Behavior Web-Based Survey (KYRBS) [11].

\section{METHODS}

\section{Participants}

Data for this study were derived from the 2011-2018 KYRBS [11]. Since 2005, the KYRBS has been conducted annually by the national Ministry of Education, the Ministry of Health and Welfare, and the Korea Centers for Disease Control and Prevention. Its main objective is to obtain knowledge about various aspects of the health status of adolescents in South Korea. To ensure the representativeness of the annual samples, the KYRBS uses a stratified sampling and proportional allocation method to collect data from 800 middle and high schools (400 each) at 44 locations. The students voluntarily participate in the self-report web-based survey, which they complete and submit in their schools' computer laboratories. Further, the survey is completed anonymously. Of the 550,221 respondents of the KYRBS from 2011 to 2018, data from 404 adolescents who had a mother and/or father of North Korean origin were pooled. A propensity score matching method was used to balance the two groups' observed demographic covariates (South vs. North Korean-family), and propensitymatched samples were extracted for analysis. Propensity scores were extracted through logistic regression; subsequently, propensity score matching was performed using the nearest neighbor matching method. Three times as many South Korean adolescents as adolescents from North Korean families were sampled using sex, survey year, school year, and place of residence as the matching variables. In total, data from 1,616 students (1,212 adolescents from South Korean families and 404 adolescents from North Korean families, 976 of whom were male and 640 females, with a mean age of $15.3 \pm 1.74$ years) were used in the analysis. The Institutional Review Board of the Korea Centers for Disease Control and Prevention approved the KYRBS (2014-06EXP-02-P-A).

\section{Measurements}

\section{Parents' nativity}

This was assessed by "yes" or "no" answers to the question: "Was your father (mother) born in South Korea?" Respondents were grouped into South Korean families (both parents born in South Korea) or North Korean families (at least one parent born in North Korea).

\section{Suicide attempts}

Suicide attempts were assessed using the responses to the question: "Have you attempted suicide during the past 12 months?" Response options were "yes" or "no."

\section{Alcohol use or tobacco use}

This was assessed by responses to the questions: "Have you used alcohol during the past 12 months?" and "Have you smoked even one puff of a cigarette, cigar, or pipe during the past 12 months?" Response options to both questions were "yes" or "no."

\section{Health status}

Health status was measured by three variables (self-perceived global health, satisfaction with sleep, and self-assessed depression). Self-perceived health was assessed using the responses to the following global question: "What do you usually think about your health condition?" Response options were on a five-point scale, where $1=$ very healthy, $2=$ healthy, 3 =average, 4 =unhealthy, and 5=very unhealthy. Self-perceived sleep satisfaction was assessed with the responses to the following question: "In the last week, how satisfactory was your sleep in terms of relieving your fatigue?" and response options were rated on a five-point scale, where $1=$ very satisfactory, $2=$ satisfactory, $3=$ average, $4=$ unsatisfactory, and 5= very unsatisfactory. Those who chose options " 1 " or " 2 " for both questions were identified as "healthy" or "satisfied," respectively. Depressive symptoms were assessed with responses to the following question: "During the past 12 months, did you ever feel so sad or hopeless almost every day for two weeks or more, that you stopped doing some of your usual activities?" and the response options were "yes" or "no."

\section{Six sociodemographic characteristics}

The sociodemographic variables were sex, school year (from seventh through twelfth year, i.e., middle school first year through high school third year), place of residence (large, small or mid-sized city, or rural area), and household type (has a nuclear family or lives with other relatives, with friends/ alone/in a dormitory, or in a facility). Perceived family socioeconomic status and perceived academic achievement were 
assessed on five-point Likert-type scales. Responses were categorized as $1=$ low, 2, 3=middle, and 4, $5=$ high.

\section{Statistical analysis}

The South and North Korean respondents were compared according to their personal characteristics using independent $\mathrm{t}$-tests and chi-squared tests for contingency as appropriate. Logistic regression analysis was performed to determine the likelihood of suicide attempts between the groups while and without controlling for the effects of sex, school year, place of residence, and survey year. Bivariate logistic regression was performed to estimate the odds ratios (OR) of the variables associated with suicide attempts for each group, and the OR and $95 \%$ confidence intervals (CIs) were calculated. Subse-

Table 1. Personal characteristics of North Korean $(\mathrm{N}=404)$ and South Korean $(\mathrm{N}=1,212)$ family adolescents

\begin{tabular}{|c|c|c|c|}
\hline Variable & $\begin{array}{l}\text { North Korean- } \\
\text { family, N (\%) }\end{array}$ & $\begin{array}{l}\text { South Korean- } \\
\text { family, N (\%) }\end{array}$ & $\begin{array}{c}\mathrm{p}- \\
\text { value }\end{array}$ \\
\hline Sex* & & & $>0.99$ \\
\hline Male & $244(60.4)$ & $732(60.4)$ & \\
\hline Female & $160(39.6)$ & $480(39.6)$ & \\
\hline Age $[\text { mean }(\mathrm{SD})]^{\dagger}$ & $15.7(1.8)$ & $15.2(1.7)$ & $<0.0001$ \\
\hline School year* & & & $>0.99$ \\
\hline Middle school 1st & $43(10.64)$ & $129(10.64)$ & \\
\hline Middle school 2nd & $66(16.34)$ & $198(16.34)$ & \\
\hline Middle school 3rd & $77(19.06)$ & $231(19.06)$ & \\
\hline High school 1st & $68(16.83)$ & $204(16.83)$ & \\
\hline High school 2nd & $65(16.09)$ & $195(16.09)$ & \\
\hline High school 3rd & $85(21.04)$ & $255(21.04)$ & \\
\hline Place of residence* & & & $>0.99$ \\
\hline Large city & $180(44.55)$ & $540(44.55)$ & \\
\hline $\begin{array}{l}\text { Small or mid-sized } \\
\text { city }\end{array}$ & $195(48.27)$ & $585(48.27)$ & \\
\hline Rural area & $29(7.18)$ & $87(7.18)$ & \\
\hline Survey year* & & & $>0.99$ \\
\hline 2011 & $44(10.89)$ & $132(10.89)$ & \\
\hline 2012 & $38(9.41)$ & $114(9.41)$ & \\
\hline 2013 & $78(19.31)$ & $234(19.31)$ & \\
\hline 2014 & $46(11.39)$ & $138(11.39)$ & \\
\hline 2015 & $47(11.63)$ & $141(11.63)$ & \\
\hline 2016 & $44(10.89)$ & $132(10.89)$ & \\
\hline 2017 & $52(12.87)$ & $156(12.87)$ & \\
\hline 2018 & $55(13.61)$ & $165(13.61)$ & \\
\hline
\end{tabular}

*t-test, ${ }^{\dagger}$ chi-square test quently, to elucidate net relationships of sociodemographic variables to suicide attempts with contributing variables, multivariate logistic regression was performed, with suicide attempts as the dependent variable and each sociodemographic or contributing variable as the main independent variable, while controlling for confounding variables. SAS 9.3 (SAS Institute, Cary, NC, USA) was used for the analyses. Any p-values of less than 0.05 were considered statistically significant.

\section{RESULTS}

Table 1 shows the distributions of the North and South Korean respondents' personal characteristics. There were no statistically significant group differences in terms of sex, school year, place of residence, or survey year. Table 2 presents the suicide attempt rates of North and South Korean-family adolescents. Seventy-four (18.32\%) of the 404 North Korean adolescents and $32(2.64 \%)$ of the 1,212 South Korean adolescents had attempted suicide at least once during the past 12 months, and the difference was statistically significant (unadjusted $\mathrm{OR}=8.27,95 \%$ CI 5.37-12.74; adjusted $\mathrm{OR}=8.45$, 95\% CI 5.47-13.06).

Table 3 presents the ORs of the sociodemographic and contributing variables to the likelihood of suicide attempts among the North Korean adolescents. The statistically significant findings are as follows. The respondents who lived with friends, alone, or in dormitories, and the respondents who lived in facilities exhibited 2.6 times and 3.57 times higher risks of suicide attempts, respectively, compared to those who lived in nuclear families. Respondents who lived with a North Korean father were 3.38 times more likely to attempt suicide compared to those who lived with a North Korean mother. The respondents who reported higher or lower socioeconomic status, and those with higher or lower academic achievement exhibited higher risks of suicide attempts than those in the middle range. Alcohol use, tobacco use, and depressive symptoms increased the risk (3.46, 3.21, and 8.81 times, respectively) of suicide attempt relative to non-users and those without depressive symptoms. Further, low perceived health and sleep dissatisfaction increased the risk of suicide attempt compared to the reference groups. Multivariate analyses indicated that living with friends/alone/in a dormitory, low socioeconomic status, and depressive symptoms significantly increased the risk of suicide attempt (compared

Table 2. Proportions and odd ratios of suicide attempts by North Korean $(\mathrm{N}=404)$ and South Korean ( $\mathrm{N}=1,212)$ family adolescents

\begin{tabular}{cccc}
\hline Variable & $\begin{array}{c}\text { North Korean- } \\
\text { family, N (\%) }\end{array}$ & $\begin{array}{c}\text { South Korean- } \\
\text { family (reference), N (\%) }\end{array}$ & $\begin{array}{c}\text { Unadjusted } \\
\text { odds ratio (95\% Cl) }\end{array}$ \\
\hline Suicide attempt & $74(18.32)$ & $32(2.64)$ & $8.27(5.37-12.74)$ \\
\hline
\end{tabular}

*adjusted for sex, school years, place of residence, and survey year 
to the reference groups) among the North Korean-family adolescents. Table 4 presents the results of the identical analysis performed on the South Korean-family adolescents, which found that females exhibited a higher risk of suicide attempt compared to males, and those having a lower socioeconomic status had a higher risk of suicide attempt than those with a middle socioeconomic status. Alcohol and tobacco use increased the risk of suicide attempt compared to non-users,

Table 3. The risk of suicide attempt in the past year among North Korean-family adolescents $(\mathrm{N}=404)$

\begin{tabular}{|c|c|c|c|c|}
\hline \multirow{2}{*}{ Variable } & \multicolumn{2}{|c|}{ Suicide attempt } & \multirow{2}{*}{$\begin{array}{l}\text { Unadjusted odds ratio } \\
\qquad(95 \% \mathrm{Cl})\end{array}$} & \multirow{2}{*}{$\begin{array}{l}\text { Adjusted odds ratio* } \\
\qquad(95 \% \mathrm{Cl})\end{array}$} \\
\hline & Yes, N (\%) & No, N (\%) & & \\
\hline School year & $74(18.32)$ & $330(81.68)$ & $0.96(0.83-1.12)$ & $0.85(0.62-1.16)$ \\
\hline \multicolumn{5}{|l|}{ Sex } \\
\hline Male (reference) & $45(11.14)$ & $199(49.26)$ & & \\
\hline Female & $29(7.18)$ & $131(32.43)$ & $0.98(0.58-1.64)$ & $0.91(0.32-2.57)$ \\
\hline \multicolumn{5}{|l|}{ Place of residence } \\
\hline Rural (reference) & $9(2.23)$ & $20(4.95)$ & & \\
\hline Small or mid-sized city & $33(8.17)$ & $162(40.1)$ & $0.45(0.19-1.08)$ & $0.63(0.1-4.19)$ \\
\hline Large city & $32(7.92)$ & $148(36.63)$ & $0.48(0.2-1.15)$ & $0.17(0.03-1.15)$ \\
\hline \multicolumn{5}{|l|}{ Father's education } \\
\hline College degree or more (ref) & $19(4.70)$ & $56(13.86)$ & & \\
\hline High school diploma or less & $34(8.42)$ & $141(34.9)$ & $0.71(0.37-1.35)$ & $0.32(0.09-1.08)$ \\
\hline \multicolumn{5}{|l|}{ Mother's education } \\
\hline College degree or more (ref) & $10(2.48)$ & $73(18.07)$ & & \\
\hline High school diploma or less & $38(9.41)$ & $153(37.87)$ & $1.81(0.86-3.84)$ & $1.92(0.49-7.47)$ \\
\hline \multicolumn{5}{|l|}{ Household type } \\
\hline Nuclear family (ref) & $29(7.18)$ & $207(51.24)$ & & \\
\hline Other relatives & $6(1.49)$ & $33(8.17)$ & $1.3(0.5-3.37)$ & $0.38(0.05-2.81)$ \\
\hline Friends, alone, or dormitory & $16(3.96)$ & $44(10.89)$ & $2.6(1.3-5.18)^{\dagger}$ & $1.58(0.41-6.14)$ \\
\hline Facility & $23(5.69)$ & $46(11.39)$ & $3.57(1.89-6.73)^{\ddagger}$ & $1(0.28-3.62)$ \\
\hline \multicolumn{5}{|l|}{ Socioeconomic status } \\
\hline High & $18(4.46)$ & $79(19.55)$ & $2.06(1.05-4.05)^{\dagger}$ & $5.42(1.07-27.33)^{\dagger}$ \\
\hline Middle (reference) & $22(5.45)$ & $199(49.26)$ & & \\
\hline Low & $34(8.42)$ & $52(12.87)$ & $5.91(3.19-10.96)^{\ddagger}$ & $15.02(3.22-69.99)^{\ddagger}$ \\
\hline \multicolumn{5}{|l|}{ Academic achievement } \\
\hline High & $29(7.18)$ & $96(23.76)$ & $2.51(1.35-4.67)^{\ddagger}$ & $1.79(0.36-8.89)$ \\
\hline Middle (reference) & $20(4.95)$ & $166(41.09)$ & & \\
\hline Low & $25(6.19)$ & $68(16.83)$ & $3.05(1.59-5.86)^{\ddagger}$ & $1.02(0.21-5.08)$ \\
\hline Alcohol use & $61(15.10)$ & $190(47.03)$ & $3.46(1.83-6.54)^{\ddagger}$ & $1.65(0.41-6.67)$ \\
\hline Tobacco use & $52(12.87)$ & $140(34.65)$ & $3.21(1.86-5.53)^{\ddagger}$ & $3.34(0.93-11.98)$ \\
\hline \multicolumn{5}{|l|}{ Type of family } \\
\hline North Korean mother (ref) & $20(4.95)$ & $164(40.59)$ & & \\
\hline North Korean father & $42(10.40)$ & $102(25.25)$ & $3.38(1.88-6.07)^{\ddagger}$ & $0.78(0.24-2.58)$ \\
\hline Both North Korean parents & $12(2.97)$ & $64(15.84)$ & $1.54(0.71-3.33)$ & $0.51(0.12-2.14)$ \\
\hline \multicolumn{5}{|l|}{ Perceived health } \\
\hline Not healthy (reference) & $14(3.47)$ & $25(6.19)$ & & \\
\hline Healthy & $60(14.85)$ & $305(75.5)$ & $0.35(0.17-0.72)^{\ddagger}$ & $0.54(0.13-2.18)$ \\
\hline \multicolumn{5}{|l|}{ Sleep satisfaction } \\
\hline Not satisfied (reference) & $43(10.64)$ & $131(32.43)$ & & \\
\hline Satisfied & $31(7.67)$ & $199(49.26)$ & $0.48(0.28-0.79)^{\ddagger}$ & $1.35(0.48-3.79)$ \\
\hline Depressive symptoms & $60(14.85)$ & $108(26.73)$ & $8.81(4.71-16.47)^{\ddagger}$ & $19.13(5.55-65.96)^{\ddagger}$ \\
\hline
\end{tabular}

*adjusted for the effects of school year, sex, place of residence, father's education, mother's education, household type, socioeconomic status, academic achievement, alcohol use, tobacco use, family type, perceived health, sleep satisfaction, and depressive symptoms, ${ }^{\dagger} p<0.05,{ }^{\ddagger} p<0.01$ 
and those with depressive symptoms had a higher risk of suicide attempt than those without such symptoms.

\section{DISCUSSION}

We investigated the likelihoods of suicide attempt among North and South Korean adolescents, and the contributing factors using data derived from the 2011-2018 KYRBS. Our results indicated that youth from North Korean families had higher risk of suicide attempts compared to their South Korean counterparts. This result is consistent with a previous retrospective cohort study [12] reporting that those who experienced childhood adversity had a two to five times higher risk of suicide attempt compared to those without adverse childhood experiences. The distress, maltreatment, and adversity that North Korean youth experience in North Korea,

Table 4. The risk of suicide attempt in the past year among South Korean-family adolescents $(N=1,212)$

\begin{tabular}{|c|c|c|c|c|}
\hline \multirow{2}{*}{ Variable } & \multicolumn{2}{|c|}{ Suicide attempt } & \multirow{2}{*}{$\begin{array}{l}\text { Unadjusted odds ratio } \\
\qquad(95 \% \mathrm{Cl})\end{array}$} & \multirow{2}{*}{$\begin{array}{l}\text { Adjusted odds ratio* } \\
\qquad(95 \% \mathrm{Cl})\end{array}$} \\
\hline & Yes, N (\%) & No, N (\%) & & \\
\hline School year & $32(2.64)$ & $1,180(97.36)$ & $0.97(0.78-1.20)$ & $0.98(0.71-1.36)$ \\
\hline \multicolumn{5}{|l|}{ Sex } \\
\hline Male (ref) & $9(0.74)$ & $723(59.65)$ & & \\
\hline Female & $23(1.90)$ & $457(37.71)$ & $4.04(1.85-8.81)^{\ddagger}$ & $3.76(1.35-10.49)^{\dagger}$ \\
\hline \multicolumn{5}{|l|}{ Place of residence } \\
\hline Rural (ref) & $1(0.08)$ & $86(7.1)$ & & \\
\hline Small or mid-sized city & $20(1.65)$ & $565(46.62)$ & $3.04(0.4-22.95)$ & $1.93(0.2-18.24)$ \\
\hline Large city & $11(0.91)$ & $529(43.65)$ & $1.79(0.23-14.01)$ & $2.08(0.21-20.18)$ \\
\hline \multicolumn{5}{|l|}{ Father's education } \\
\hline College degree or more (ref) & $17(1.40)$ & $575(47.44)$ & & \\
\hline High school diploma or less & $8(0.66)$ & $393(32.43)$ & $0.69(0.29-1.61)$ & $0.49(0.14-1.72)$ \\
\hline \multicolumn{5}{|l|}{ Mother's education } \\
\hline College degree or more (ref) & $12(0.99)$ & $486(40.1)$ & & \\
\hline High school diploma or less & $13(1.07)$ & $481(39.69)$ & $1.10(0.49-2.42)$ & $1.13(0.36-3.55)$ \\
\hline \multicolumn{5}{|l|}{ Household type } \\
\hline Nuclear family (ref) & $32(2.64)$ & $1,135(93.65)$ & & \\
\hline Other relatives & $0(0)$ & $8(0.66)$ & & \\
\hline Friends, alone, or dormitory & $0(0)$ & $35(2.89)$ & & \\
\hline Facility & $0(0)$ & $2(0.17)$ & & \\
\hline \multicolumn{5}{|l|}{ Socioeconomic status } \\
\hline High & $5(0.41)$ & $99(8.17)$ & $2.39(0.89-6.46)$ & $4.25(1.15-15.72)^{\dagger}$ \\
\hline Middle (ref) & $22(1.82)$ & $1,043(86.06)$ & & \\
\hline Low & $5(0.41)$ & $38(3.14)$ & $6.24(2.24-17.36)^{\ddagger}$ & $5.26(0.87-31.86)$ \\
\hline \multicolumn{5}{|l|}{ Academic achievement } \\
\hline High & $6(0.50)$ & $143(11.8)$ & $1.79(0.71-4.52)$ & $1.46(0.38-5.56)$ \\
\hline Middle (ref) & $21(1.73)$ & $897(74.01)$ & & \\
\hline Low & $5(0.41)$ & $140(11.55)$ & $1.53(0.57-4.11)$ & $0.75(0.16-3.59)$ \\
\hline Alcohol use & $25(2.06)$ & $522(43.07)$ & $4.50(1.93-10.49)^{\ddagger}$ & $4.89(1.39-17.27)^{\dagger}$ \\
\hline Tobacco use & $14(1.16)$ & $213(17.57)$ & $3.5(1.73-7.21)^{\ddagger}$ & $1.56(0.54-4.53)$ \\
\hline \multicolumn{5}{|l|}{ Perceived health } \\
\hline Not healthy (ref) & $4(0.33)$ & $58(4.79)$ & & \\
\hline Healthy & $28(2.31)$ & $1,122(92.57)$ & $0.36(0.12-1.07)$ & $1.47(0.22-9.72)$ \\
\hline \multicolumn{5}{|l|}{ Sleep satisfaction } \\
\hline Not healthy (ref) & $17(1.40)$ & $487(40.18)$ & & \\
\hline Healthy & $15(1.24)$ & $693(57.18)$ & $0.62(0.31-1.25)$ & $1.14(0.42-3.09)$ \\
\hline Depressive mood & $24(1.98)$ & $316(26.07)$ & $8.20(3.65-18.45)^{\ddagger}$ & $6.85(2.28-20.58)^{\ddagger}$ \\
\hline
\end{tabular}

*adjusted for the effects of school year, sex, place of residence, father's education, mother's education, household type, socioeconomic status, academic achievement, alcohol use, tobacco use, family type, perceived health, sleep satisfaction, and depressive symptoms, ${ }^{\dagger} p<0.05,{ }^{\ddagger} p<0.01$ 
during their escape, and after settling in South Korea could be the underlying causes affecting their higher risk of suicide attempt.

We then examined factors that contributed to suicide attempt by family type (North vs. South Korean-family). Some factors were similar in both groups, such as low socioeconomic status, alcohol use, tobacco use, and having depressive symptoms. However, the contributions of other factors were different between the two groups. Specifically, high socioeconomic status, high academic achievement, and household type increased the risk while perceived health and sleep satisfaction decreased the risk of suicide attempt among the North Korean adolescent respondents (compared to the reference groups), whereas South Korean-family female adolescents had higher risk of suicide attempt than males.

A low socioeconomic status has consistently been associated with suicidal behaviors [13]. Our results found that a low socioeconomic status increased the risk of suicide attempt for both groups of adolescents, which could possibly be explained by their social disadvantages. Our data also revealed that alcohol and tobacco use increased the risk of suicide attempt for both groups of adolescents, supporting the results of previous studies, a considerable number of which found that alcohol and tobacco use were associated with suicidal behaviors [14,15]. According to a meta-analysis [15], the ORs of smokers with suicidal behaviors (i.e., suicidal ideation, suicide plans, and suicide attempts) ranged from 2.05 to 2.84 . The association between smoking and suicidal behaviors is believed to be explained by unobserved confounding factors between the two variables [16]. A previous study [14] conducted in Korea found that binge drinking was a major factor associated with suicidal behaviors among Korean adolescents. Our results also found a higher risk of suicide attempt among adolescents (in both groups) who had consumed alcohol (at least one time) during the past year, which suggests that even a small amount of alcohol consumption may relate to suicidal behaviors in Korean youth. These results do not necessarily imply a causal relation between tobacco or alcohol use and suicidal behavior, but do show that these behaviors help explain suicidal behavior.

Our analyses found that depressive symptoms increased the risk of suicide attempt for both groups of adolescents. Kerr et al. [17] found that adolescents' depressive symptoms independently influenced suicidal behavior. Arguably, the South Korean respondents' suicide attempts could be related to cultural factors, such as academic stress, psychological distress, and feelings of worthlessness [18]. The North Korean respondents' traumatic experiences, forced repatriation, acculturative stress, and assimilation obstacles have been associated with their poor mental health [5], which might increase their risk of suicide attempt.

A distinct factor contributing to the risk of suicide attempt for the North Korean respondents was household type (i.e., living with friends, alone, or in a dormitory or living in a facility). Previous studies have also found that household type was associated with the risk of suicidal behaviors; for example, one recent study [19] found that children and adolescents in care settings (e.g., foster care, kinship care, and so on) had higher risk of suicide attempt. This increased risk could be explained by these children's relatively high exposure to risk factors such as physical or sexual abuse, neglect, or family disorganization [20]. Moreover, North Korean refugees living with family members have fewer psychiatric problems than those living separately [21]; family situation may greatly affect North Korean refugee youth's risk of suicide attempt. This finding supports Park et al. [9], who found that weaker family cohesion increased suicidal ideation in North Korean refugee youth in South Korea.

We also found that having a North Korean father (but not mother) was associated with a higher risk of suicide attempt compared to having a North Korean mother (but not father). It is often difficult for North Korean refugees to find employment in Korea because of prejudice against them [20]. Even when they find work, they are paid less than South Koreans for equivalent labor; the average monthly incomes of a North Korean refugee and South Korean national are approximately USD 2,280 and 3,070, respectively [22]. In addition, Korean marriage patterns tend to lean toward women marrying men who have a higher socioeconomic status (i.e., hypergamous) [23]. Therefore, adolescents with North Korean refugee fathers seem relatively likely to have lower family socioeconomic status, which may, in turn, increase their risk of suicide attempt [24] compared to those with a North Korean refugee mother married to a South Korean.

The North Korean respondents with high socioeconomic status and those with low or high academic achievement had higher risks of suicide attempt than those in the middle categories. Socioeconomic status and academic achievement have been inversely related to suicidal behavior [13]. However, our results were not linear, as those with high socioeconomic status and academic achievement had higher risks of suicide attempt than those in the mid-range. One way that North Koreans can improve their social status in South Korea is through educational attainment; however, those who attend school suffer from adaptation difficulties [4]. South Korean adolescents face strong academic pressures and stressors that have been related to suicidal behavior [25], and a major stressor among high socioeconomic status adolescents in Korea seems to be academic pressure [26]. Therefore, along with the other obstacles faced by North Korean-family ado- 
lescents as they adapt to South Korea, academic stress could be an additional factor contributing to a higher risk of suicide attempt.

Relatively good perceived health and sleep satisfaction were associated with a lower risk of suicide attempt among the North Korean respondents compared to those with poor perceived health and poor sleep. A previous study by Isaac et al. [27] found that low health-related self-efficacy was associated with lifetime and recent suicidal ideation, attempts, and future intentions. Further, based on the results of a longitudinal study [28], poor perceived sleep quality may correlate with increased risk of suicide after controlling for the effect of depressive symptoms. These previous studies imply that better perceived health and sleep protect North Korean-family adolescents from the risk of suicide attempt. One problem among North Korean-family adolescents is that they are more likely to experience childhood adversity involving malnutrition, leading to their physical condition and growth being lower than that of South Korean adolescents [4]. Therefore, self-perceived health and sleep satisfaction may have more influence on the risk of suicide attempt for them than their South Korean counterparts.

A distinct contributing factor to suicide attempt in the South Korean group was sex such that females had a higher risk of suicide attempt than males. A previous study [29] investigated the trends in suicide among Korean adolescents and found that the suicide rate began increasing among females but not males in 2000. Perhaps female adolescents are more sensitive than male adolescents to the combination of risk factors that they face, such as depressive symptoms, academic stress, and school violence [30].

We performed a multivariate analysis because suicidal behaviors are inter-correlated. This analysis revealed that the confounding variables, socio-economic status (low and high) and depressive symptoms, still influenced the likelihood of suicide attempt (compared to the reference groups) in the North Korean group. Among the South Korean respondents, being female, a high socioeconomic status, alcohol use, and having depressive symptoms were associated with a relatively higher risk of suicide attempt. When the influences of the confounding variables were controlled, a high socio-economic status was significantly associated with a higher risk of suicide attempt. This association could be explained by the academic stress experienced by adolescents who come from families with high socio-economic status in Korea [25]. The factors were clearly different compared to those that physicians and other experts tend to consider when developing interventions against youth suicide in Korea.

Despite its valuable findings, this study had several limitations. First, its data were cross-sectional and hence, we could not draw causal inferences about the statistical results. Second, a considerable number of the variables were measured using one question, such as the measure of depressive symptoms. Future studies should use other tools or questionnaires and attempt to replicate our findings. Subsequently, our data were self-ratings, and, therefore, the responses might be biased.

\section{CONCLUSION}

This study examined differences in suicide attempt between South and North Korean-family adolescents residing in South Korea. We have found statistically significant factors contributing to the risk of suicide attempt for each group. Some factors were similar, and others were distinctly different between the two groups of adolescents. These similarities and differences need to be integrated into interventions aimed at suicide prevention. In particular, interventions for North Koreanfamily adolescents should consider their socioeconomic status (particularly low socioeconomic status) along with a focus on depressive symptoms.

\section{Acknowledgments}

This work was supported by a National Research Foundation of Korea (NRF) grant funded by the Korean Government (NRF-2016R 1D1A1B03931297).

\section{Conflicts of Interest}

The authors have no potential conflicts of interest to disclose.

\section{Author Contributions}

Conceptualization: Subin Park, Soo Jung Rim. Data curation: Subin Park, Min Geu Lee. Formal analysis: Min Geu Lee. Funding acquisition: Subin Park. Investigation: Subin Park, Soo Jung Rim, Min Geu Lee. Methodology: Min Geu Lee. Project administration: Subin Park. Supervision: Subin Park. Validation: Soo Jung Rim. Visualization: Soo Jung Rim. Writingoriginal draft: Soo Jung Rim. Writing—review \& editing: Subin Park.

\section{ORCID iDs}

$\begin{array}{ll}\text { Soo Jung Rim } & \text { https://orcid.org/0000-0003-4938-4116 } \\ \text { Min Geu Lee } & \text { https://orcid.org/0000-0003-2916-7421 } \\ \text { Subin Park } & \text { https://orcid.org/0000-0002-4623-9899 }\end{array}$

\section{REFERENCES}

1) Ministry of Unification. Number of North Korean defectors by age group. 2016 [cited 2019 Sept 1]. Available from URL: https://www. unikorea.go.kr/unikorea/business/NKDefectorsPolicy/status/lately/.

2) Cho YA, Kim YH. [Predictors of mental health risks in newly resettled North Korean refugee women]. Korean J Woman Psychol 2010; 15:509-527.

3) Kim HK, Shin HK. A comparison of the mental health problems of North Korean adolescent defectors and South Korean adolescents: focused on gender and age. Korean J Woman Psychol 2015;20:347367.

4) Hong K. Towards an understanding of North Korean adolescent refugees in South Korea. Travel Trade J 2012;15:186-204.

5) Choi SK, Min SJ, Cho MS, Joung H, Park SM. Anxiety and depression among North Korean young defectors in South Korea and their 
association with health-related quality of life. Yonsei Med J 2011;52: 502-509.

6) Emery CR, Lee JY, Kang C. Life after the pan and the fire: depression, order, attachment, and the legacy of abuse among North Korean refugee youth and adolescent children of North Korean refugees. Child Abuse Negl 2015;45:90-100.

7) Kim MJ, Yu SY, Kim S, Won CW, Choi H, Kim BS. Health behavior and factors associated with depression in North Korean adolescent defectors in South Korea: The Korea Youth Risk Behavior WebBased Survey, 2011-2014. Korean J Fam Med 2017;38:256-262.

8) Kessler RC, Borges G, Walters EE. Prevalence of and risk factors for lifetime suicide attempts in the National Comorbidity Survey. Arch Gen Psychiatry 1999;56:617-626.

9) Park S, Rim SJ, Jun JY. Related factors of suicidal ideation among North Korean refugee youth in South Korea. Int J Environ Res Public Health 2018;15:E1694.

10) Ahn JH, Kim WH, Choi HJ, Jeon JY, Song IG, Bae JN. Stigma of mental illnesses as perceived by north korean defectors living in South Korea. Psychiatry Investig 2015;12:9-15.

11) Korea Centers for Disease Control and Prevention. Korea youth risk behaviour web-based survey 2011-2018 [cited 2019 Sept 1]. Available from URL: https://www.cdc.go.kr/yhs/home.jsp?id=m03_05.

12) Dube SR, Anda RF, Felitti VJ, Chapman DP, Williamson DF, Giles WH. Childhood abuse, household dysfunction, and the risk of attempted suicide throughout the life span: findings from the Adverse Childhood Experiences Study. JAMA 2001;286:3089-3096.

13) Rehkopf DH, Buka SL. The association between suicide and the socio-economic characteristics of geographical areas: a systematic review. Psychol Med 2006;36:145-157.

14) Byeon KH, Jee SH, Sull JW, Choi BY, Kimm H. Relationship between binge drinking experience and suicide attempts in Korean adolescents: based on the 2013 Korean Youth Risk Behavior Webbased Survey. Epidemiol Health 2018;40:e2018046.

15) Poorolajal J, Darvishi N. Smoking and Suicide: a meta-analysis. PLoS One 2016;11:e0156348.

16) Boden JM, Fergusson DM, Horwood LJ. Cigarette smoking and suicidal behaviour: results from a 25 -year longitudinal study. Psychol Med 2008;38:433-439.

17) Kerr DC, Reinke WM, Eddy JM. Trajectories of depressive symptoms and externalizing behaviors across adolescence: associations with histories of suicide attempt and ideation in early adulthood.
Suicide Life Threat Behav 2013;43:50-66.

18) Juon HS, Nam JJ, Ensminger ME. Epidemiology of suicidal behavior among Korean adolescents. J Child Psychol Psychiatry 1994;35: 663-676.

19) Evans R, White J, Turley R, Slater T, Morgan H, Strange H, et al. Comparison of suicidal ideation, suicide attempt and suicide in children and young people in care and non-care populations: systematic review and meta-analysis of prevalence. Child Youth Serv Rev 2017; $82: 122-129$.

20) Rushton A, Minnis $H$. Residential and foster family care. In Rutter M, Taylor E, editors. Child and adolescent psychiatry. Oxford: Blackwell;2002. p.359-372.

21) Jeon WT. Issues and problems of adaptation of North Korean defectors to South Korean society: an in-depth interview study with 32 defectors. Yonsei Med J 2000;41:362-371.

22) Korea Hana Foundation. 2018 Settlement survey of North Korean refugees in South Korea. Seoul: Korea Hana Foundation;2018.

23) Smits J, Park H. Five decades of educational assortative mating in 10 East Asian societies. Soc Forces 2009;88:227-255.

24) Lee SU, Oh IH, Jeon HJ, Roh S. Suicide rates across income levels: retrospective cohort data on 1 million participants collected between 2003 and 2013 in South Korea. J Epidemiol 2017;27:258-264.

25) Zong S. A study on adolescent suicide ideation in South Korea. Procedia Soc Behav Sci 2015;174:1949-1956.

26) Park S, Jang H, Lee ES. Major stressors among Korean adolescents according to gender, educational level, residential area, and socioeconomic status. Int J Environ Res Public Health 2018;15:E2080.

27) Isaac V, Wu CY, McLachlan CS, Lee MB. Associations between health-related self-efficacy and suicidality. BMC Psychiatry 2018; 18:126.

28) Bernert RA, Turvey CL, Conwell Y, Joiner TE Jr. Association of poor subjective sleep quality with risk for death by suicide during a 10-year period: a longitudinal, population-based study of late life. JAMA Psychiatry 2014;71:1129-1137.

29) Choi KH, Kim DH. Trend of suicide rates according to urbanity among adolescents by gender and suicide method in Korea, 19972012. Int J Environ Res Public Health 2015;12:5129-5142.

30) Kim JY, Jang YE, Seo JY, Park JM. A study on the effect of school violence to adolescent's suicidal behaviors: mediating effect of in depression. J Adolescent Welfare 2014;16:83-110. 